ASSOCIATION OF PERINATAL FACTORS WITH

1381 PERIVENTRICULAR HEMORRHAGE (PVH) IN VERY LOW BIRTHWEIGHT (VLBW) NEONATES J.R. Evans, A.C. Allen, D.A. Stinson, M.J. Vincer, C.G. Nwaesei, B.St.J. Brown, Perinatal factors associated with PVH were prospectively surveyed in 157 consecutively born VLBW inborn infants. Diagnosis of PVH was determined by cranial ul trasound (148 cases) or autopsy ( 9 cases). Ten infants with major anomalies and four infants who had no ultrasound or autopsy were excluded. The overall incidence of PVH was $29.9 \%, 22.9 \%$ minor (Gr $1-2)$ and $7 \%$ major ( $\mathrm{Gr} 3-4)$. Mean gest age (GA) and ( $\mathrm{Gr} 1-2)$ and $7 \%$ major $(\mathrm{Gr} 3-4)$. Mean gest age $(\mathrm{GA})$ and who developed PVH: $974 \pm 227 \mathrm{~g}$ and $27 \pm 2.6$ wh vs $1150 \pm 269 \mathrm{~g}$ and who developed PVH: $974 \pm 227 \mathrm{~g}$ and $27 \pm 2.6$ wk vs $1150 \pm 269 \mathrm{~g}$ and
$30 \pm 3.3$ wh respectively. Mortality was $13.6 \%$ in infants with no PVH, $22.2 \%$ with minor, and $45.5 \%$ with major PVH.

With partial correlation analysis, highly significant $(p<0.001)$ perinatal factors found to be independently associated with PVH were vaginal delivery, hyal ine membrane disease (HMD), positive pressure ventilation (PPV) and pneumothorax. The reduced incidence of PVH associated with caesarean section (CS) was noted only in infants <30 wk GA. Caesarean section (CS) was noted only in infants $<30$ wk Major PVH occurred exclusively in infants who had no or
suboptimal $(<24 \mathrm{hr})$ prenatal steroids $(p<0.03)$, developed severe HMD $(p<0.001)$ and required PPV $(p<0.001)$. In attemptin to reduce the incidence and severity of $\mathrm{PVH}$, attention should be focused on the prevention of prematurity and HMD. The suggestion that CS prevents PVH in extremely premature infants could be established only with a randomized controlled trial.

Post natal (PN) evolution of anthropometric variable 1382 (AV) in preterm infants (PI) fed breast milk (BM). Alistair G S. PHILIP). Hop. Debrousse Dept of Neonatologie, LYON, 35PI were studied : 20 appropriate for gestationel age (AGA), GA; $29 \pm 1.4$ wks, birth weight. (BW) $: 1301,2 \pm 256 \mathrm{~g}$, and 15 small
for GA(SGA), GA: $34 \pm 2,4$ wks, BW $: 1323,3 \pm 255 \mathrm{~g}$. They were

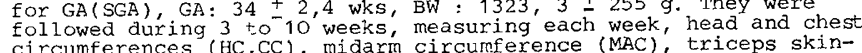
fold thickness ('TSKF), derived arm muscle and fat areas (AMA,AFA). correlations were made between $G A$ and $A V$, and then compared with fetus values, (previously described on 74 AGA and 22 SGA at d 1 of
life) as follows :

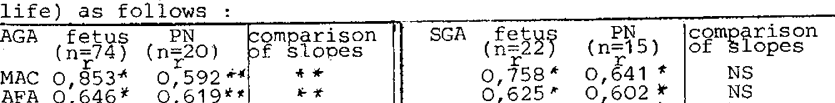

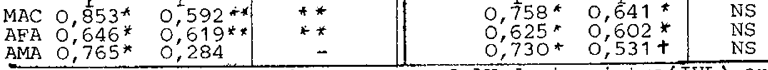
When fed BM, the growth natterns of AV during intra(IUL) ans ex-
tra uterine iffe (EUL) do not differ in SGA Infants, but show a
significant lower growth velocity in AGA infants during EUL: MAC Shows an important reduction mainly due to a lower fat compartment ting AV and the degree of maturity was established for IUL: this model does not apoly to EUL. A new model is proposed : $\mathrm{GA}=0,276$
$\mathrm{HC}+0,723 \mathrm{CC}-0,122 \mathrm{MAC}+0,5 \mathrm{TSKF}+10,173(\mathrm{r}=0,867, \mathrm{p} 0,001)$. MAC and SKF provide a simple estimation of body composition of neonates in agreement with carcass studies, and a useful tool to determine the degree of maturity of a newborn ( $*: p<0,001$; * * $\mathrm{p}<0,01$; $t \mathrm{p}<0,05)$.

ROLONGED TREATMENT OF THE PATENT DUCTUS ARTERIOSUS 01383 (PDA)WITH INDOMETHACIN(IM)Mitzi G. Ferguson, Philip Batson) Univ of Mississippi Med Ctr., Dept of Peds, Jackson, MS IM has been widely accepted as a safe and effective method for closure of the PDA in the very low birth weight (VLBW) for closure of the PDA in the very low birth weight (VLBW)
infants. Suggestions for prolonged IM treatment in these VLBW infants have been advocated to obtain adequate closure of the PDA. Therefore, this study was undertaken as a controlled clinical trial to compare 2 dosage regimens of IM and their effectiveness in the closure of the PDA. All infants $<1500 \mathrm{gms}$ who had a $\odot$ contrast echocardiogram for a PDA were randomized to one 2 arous: maintenance (M) or non-maintenance (NM). The $M$ group received 2 doses of IM OG 12 hrs apart and were then group received 2 doses of. The NM group only received 2 doses placed on $M$ IM for 5 days. The NM group only received 2 doses study: 33 in the $M$ group and 36 in the NM group. 23/33 (70\%) in the $M$ group and $20 / 36(55 \%)$ in the NM group had negative follow-up echo after the 1st 2 doses of IM. 10 days after the initial dose of IM 5/20 in the NM group had reopened their PDA as compared to $0 / 23$ in the $M$ group $(p<0.025) .11$ infants in the $M$ group and 1 additional infant in the NM group reopened their PDA at an average age of 35 days as evaluated by clinical and radiographic criteria. The data suggests that by giving M IM for 6 days after birth, there is a lower rate of ductal reopening during the acute stage of illness. The late ductal reopening does occur in both groups although it had little clinical significance at this late stage.
$1384 \frac{\text { FISK FACTORS FOR BRONCHOPULMONARY DYSPLASIA }}{\text { Finer, Kathrine Peters, Keith Barrington, Zamir }}$ Hospital, Department of Neonatology, Edmonton, Alberta, CANADA In an effort to identify risk factors associated with the In an effort to identify risk factors associat we retrospecdevelopment of bronchopulmonary dysplasia (BPD) we retrospectively reviewed over a 5 year period the neonatal course of all 188 infants of $<1500 \mathrm{~g}$ who required mechanical ventilation for
$>24$ hours and survived at least 14 days. Infants with BPD had $>24$ hours and survived at least 14 days. Infants with BPD had
lower birth weights $(p<.001)$, shorter gestations $(p<.001)$, more frequent patent ductus arteriosus $(p=.009)$, more often required muscle relaxation $(p<.001)$, had interstitial air on $x$-ray within 7 days of birth $(p=.007)$. A discriminative analysis utilizing these variables plus sum of the daily mean airway pressure and the 2 nd week of 1 ife was compared sum of daily mean $\mathrm{A}_{-}-\mathrm{OO}_{2}$ for the 2 nd week of to the clinical criteria of the need for mechanical ventilation and an $\mathrm{FiO}_{2}>.3$ at 14 days of age for the prediction of $\mathrm{BPD}$. cohort of 35 infants. PREDICTIVE VALUE OF POSITIVE TEST ( $N=223$ )

$\begin{array}{llcc} & <1000 \mathrm{gm} & 1000-1250 \mathrm{gm} & >1250 \mathrm{gm} \\ \text { Incidence of BPD (\%) } & 72.2 & 33.8 & 21.7 \\ \text { Discriminant function (\%) } & 80 & 72.2 & 92.9 \\ \text { Clinical criteria }(\%) & 91.4 & 66.7 & 71.4\end{array}$
Clinical criteria (\%) $\quad 91.4 \quad 66.7 \quad 01.4$ The clinical criteria correctly predicted BPD in $92 \%<1000 \mathrm{gm}$,
$58.3 \%$ between $1000-1250 \mathrm{gm}$ and $85 \%>1250 \mathrm{gm}$. With a specificity and sensitivity similar to the discriminant function the use of such criteria may be helpful in identifying infants who mal benefit from therapeutic trials to prevent or ameliorate this disorder.

CEREBRAL BLOOD FLOW (CBF) AUTOREGULATION IN THE NEW1385 BORN LAMB WITH HYPOVOLEMIC HYPOTENSION WITHOUT AN ASSOCIATED ANEMIA. Gregory A. Franklin, J. Timothy O'Neill and Errol R. Alden, Department of

We have shown that the newborn lamb maintains $\mathrm{CBF}$ when mean rterial blood pressure (MAP) is lowered to $30 \mathrm{mmHg}$ by hemorarterial blood pressure (MAP) is lowered to hematocrit (HCT) and arterial $\mathrm{O}_{2}$ content $\left[\mathrm{O}_{2}\right]_{\mathrm{a}}$ fell nearly $40 \%$. Although $\mathrm{O}_{2}$ delivery $\left(\mathrm{O}_{2} \mathrm{D}\right)$ decreased, $\mathrm{O}_{2}$ consumption $\left(\mathrm{MVO}_{2}\right)$ was maintained. Because $\mathrm{HCT}$ and $\left[\mathrm{O}_{2}\right]_{a}$ are determiners of $\mathrm{CBF}$, we attempted to control those variables in 6 anesthetized lambs ( $<7$ days old). HCT was maintained within physiological limits by infusing autologous packed RBC's. $C B F$ was measured with radioactive microspheres. MAP was reduced (with a pressurized reservoir connected to a catheter in the abdominal aorta) from control to $50,40 \& 30 \mathrm{mmHg}$.

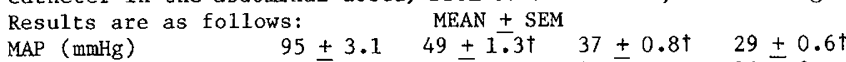

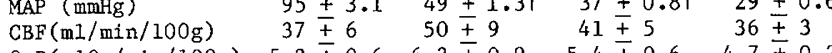
$0_{2} \mathrm{D}(\mathrm{mlO} / \mathrm{min} / 100 \mathrm{~g}) \quad 5.2 \pm 0.6 \quad 6.3 \pm 0.9 \quad 5.4 \pm 0.6 \quad 4.7 \pm 0.2$ $\mathrm{MVO}_{2}(\mathrm{mlO} / \mathrm{min} / 100 \mathrm{~g}) 2.7 \pm 0.3 \quad 4.3 \pm 0.4 * \quad 4.1 \pm 0.5 * 3.6 \pm 0.4$ †P $<0.01 ; * \mathrm{P}<0.05$

$\mathrm{CBF}$ and $\mathrm{O}_{2} \mathrm{D}$ were maintained and $\mathrm{MVO}_{2}$ increased in the newborn lamb model of hypotension without anemia. Since the HCT and $\left[0_{2}\right]_{2}$ were well controlled, this study documents that the new-

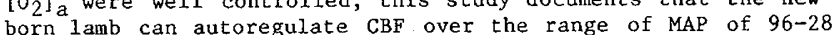
born lamb can autoregulate (non-anemia), MV $0_{2}$ increases. If $\mathrm{O}_{2}$ demand is as great in anemic-hypotensive newborns; the inability of $\mathrm{O}_{2} \mathrm{D}$ to adequately supply this demand may result in ischemia.

\section{PROSTAGLANDIN RESPONSE TO INDOMETHACIN}

1386 THERAPY FR RATINT DUCTUS ARTERTOSUS IN

David R. Fulton, Ronald Berninger, Kyung J. Chung, Dan Kong, David Watkins, Myron Peterson. (Spon. by Jane G. Schaller) Tufts Univ. Sch. of Med., The Floating Hosp., Dept. of Ped., Boston.

To elucidate the relationship between ductal patency (PDA), plasma prostaglandins (PG) and indomethacin (IN), 55 infants $<1750 \mathrm{gms}$ at birth were monitored prospectively for a hemodynamically significant PDA by exam, CXR, echo/doppler and ventilator dependence. Six received IN $0.2 \mathrm{mg} / \mathrm{kg} /$ dose for 3 doses at $12 \mathrm{hr}$. intervals. Plasma for $\mathrm{IN}$, thromboxane $\mathrm{B}_{2}$ (' $\mathrm{I}$ ) and 6 -keto-PGF $1(6 \mathrm{~K})$, the stable metabolite of prostacyclin, IN. Control and $12 \mathrm{hr}$ interval mean results were:

$\begin{array}{ccccc}\frac{\mathrm{Hr} \text { after } \mathrm{IN}}{0} & \frac{\overline{\mathrm{IN}}(\mathrm{ng} / \mathrm{ml})}{0} & \frac{\overline{\mathrm{T}}(\mathrm{pg} / \mathrm{ml})}{80} & \frac{\overline{6 \mathrm{~K}}(\mathrm{pg} / \mathrm{ml})}{132} \\ 12 & 268 & & 60 & 133 \\ 24 & & 346 & 55 & 134 \\ 36 & 418 & 60 & 132\end{array}$

The PDA closed in all infants within $24 \mathrm{hr}$. The data indicate that PDA closure correlated with rising IN concentration and decreased $T$ synthesis while $6 \mathrm{~K}$ did not change. This differential decreased s P oxygenase at different anatomic sites and that circulating $\mathrm{T}$ may predict efficacy of PDA closure by IN. 